\title{
Entrevista a Raúl Gagliardi.
}

Por: Diego Campos

En el $\mathrm{V}$ encuentro de Enseñanza de la Biología y Educación Ambiental, celebrado los días 17, 18 y 19 de Junio del año en curso, los miembros del comité editorial de la revista del Departamento de Biología de la Universidad Pedagógica Nacional entrevistaron al conferencista internacional Raúl Galgliardi.

El profesor Gagliardi ha realizado estudios en Biología Marina, Pesquera, Molecular, Vegetal y Teórica, entre otros. Asimismo trabajó en el Laboratorio de Didáctica y Epistemología de Ciencias de Andrés Giordan; en el programa mundial de lucha contra el SIDA de la Organización Mundial de la Salud; en la Organización Internacional del Trabajo en orientación profesional y problemas del desarrollo; en la Oficina Internacional de Educación y en los programas de pregrado y posgrado en China así como en distintos proyectos en Asia y América latina.

A lo largo de su carrera profesional se ha desempeñado en el campo de la educación y uno de sus trabajos más reconocidos es la formulación de conceptos estructurantes para la enseñanza de la biología y la identificación de obstáculos de aprendizaje para la enseñanza de las ciencias. Actualmente, trabaja en el Instituto Rosario de Ciencias de la Educación como Director y les enseña a los docentes de las escuelas, ubicadas en barrios marginales de Rosario (Argentina), la importancia de las ciencias para el mejoramiento de la calidad de vida.

Diego Campos: ¿Cuáles podrían ser los Conceptos Estructurantes para enseñar Ecología en los países Latinoamericanos?

Raúl Gagliardi: Para enseñar ecología yo te diría que son los conceptos estructurantes similares a los de todo el mundo, la ecología es una ciencia y los presupuestos básicos y los conceptos fundamentales podría decirse son los mismos, por ejemplo: ciclo de materia, flujo de energía, población mendeliana, estructura y dinámica en poblaciones, factor limitante; grandes conceptos que permiten comprender un ecosistema.

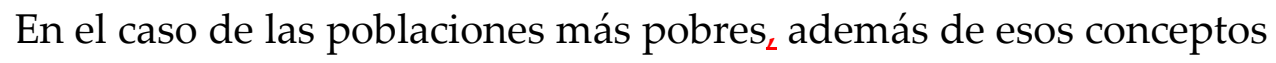
para comprender el funcionamiento, creo que también hay que introducir o enfatizar los problemas específicos; por un lado, con 
una mejor utilización de los recursos renovables para mejorar la situación económica, por ejemplo el reciclado, que en Argentina se llama cartoneo, el cual se puede mejorar pasando de cartoneo individual a una cooperativa o una pequeña empresa $a_{\llcorner}$con lo cual con un pequeño esfuerzo más la persona puede obtener el doble, así un kilo de botella de plástico, que se le pagaba al cartonero a un peso argentino en el 2006, puede convertirse en 50 o 60 pesos si la persona lo vende en cantidad y separa los distintos tipos de plásticos que hay. Al mismo tiempo, si el cartonero se organiza y planifica, cuida su salud en todo ese tipo de cosas que están ligadas a los riesgos que significa trabajar con la basura (las toxinas que puede haber, los roedores, los insectos), lo cual es fundamental para alguien que trabaja en la basura o que vive cerca de ella mejorando de forma integral su calidad de vida.

La ecología tiene que ser científica en sus fundamentos, naturalmente adaptada a las condiciones de la población y debe tener en cuenta los fenómenos locales. El caso de las minas constituye otro ejemplo allí el fenómeno ecológico es fundamental para que la gente comprenda y prevenga las enfermedades provocadas por la contaminación del aire o las grandes industrias químicas. El exceso de fertilizantes de nitratos que se acumula en las capas freáticas es otro ejemplo $\mathrm{o}_{\llcorner}$pues la Argentina es una gran cuenca que termina en el río de la Plata, esa acumulación hace que en la zona no haya agua potable y la gente tome agua contaminada con esos nitratos. Esta situación produce una enfermedad en los niños que se llama hipoglinemia, la cual consiste en que_los nitratos se ligan a la hemoglobina e impiden que ésta se combine con el oxígeno, haciendo que el niño presente tez de color azul. A pesar de que al niño le colocan oxígeno, muere de todos modos. Esto no es un fenómeno local sino un fenómeno que está sucediendo a 500 kilómetros de donde se tomó el agua.

No se trata de alertar a la población y decirle lo que sucede sino también hay que darle los conocimientos para que comprenda el fenómeno y pueda encontrar y aplicar las soluciones, las cuales deben ser sustentables, durables y permanentes para lo cual es necesario una solución económica.

DC: Eso nos deja en un plano en el que no tiene sentido enseñar ciencia si no estamos mejorando la calidad de vida o no estamos dando solución a problemas reales de un contexto inmediato.

RG: Debemos enseñar ciencias de muy buena calidad y hacer que el alumno la aplique y comprenda ese fenómeno, es decir, se trata de enseñar la mejor ciencia, pero que se aplique a la realidad concreta, no dar al público sistemas teóricos sino estudiar al ecosistema del lugar, lo cual constituye un reto mayor en la búsqueda de soluciones. 
DC: La UNESCO o la FAO tienen cierta ingerencia en el diseño de currìculos en ciencia. ¿Ellos tienen la iniciativa de incorporar los conceptos estructurantes en el diseño de estos currículos para el mejoramiento de la calidad de vida?

RG: Bueno yo diría que sí, que la intención es mejorar la calidad de vida de la población mundial, dicha intención está en todos los programas y muchas veces hay programas diferentes, por ejemplo, la FAO tiene buenos programas para el desarrollo rural y mejora de las condiciones de vida para el campesino, además existen programas de conservación de alimentos y agricultura; la OMS tiene programas de lucha contra los insectos y las enfermedades transmitidas. Ahora se cuenta con el programa contra Malaria, Tuberculosis, SIDA; organizaciones como la UNESCO y UNICEF, que propenden por el cuidado de los niños y las enfermedades infantiles y otros programas que están vinculados con el uso de vivienda pero cada uno está funcionando más o menos de forma aislada, lo cual conlleva a pensar en la necesidad de crear un programa integral, es decir, que al mismo tiempo trate la educación y la salud, el medio ambiente, la agricultura , la organización de micro empresas, la utilización de informática , y que sea un solo grupo el que vaya a realizar esta labor.

Por otra parte, desconozco lo que se está haciendo ahora en materia de educación en el ambiente. En una época se hacía demasiado eco en los aspectos de protección al mismo, tratando de sensibilizar a los alumnos, lo cual es importante, pero creo que es alejar al alumno de la situación, el alumno tiene que comprender qué es su propio ambiente, mejorarlo o utilizarlo mejor, está muy bien proteger a las ballenas pero es mejor proteger a los bebes que se están muriendo, más cuando se mueren por causa del daño ambiental y estoy en desacuerdo con las grandes campañas por las ballenas porque me parece que no hay que decirle a alguien que está hambreado que salga a luchar por ellas.

Un ejemplo de la importancia de la educación en el conocimiento de los factores ambientales que causan enfermedades, es una buena campaña de educación para el ambiente interno. Por ejemplo, el humo en las casas, provocado por la cocina o la combustión de leña, es la causa más influyente en las enfermedades respiratorias y oftálmicas en el tercer mundo.

El proyecto que estoy tratando de desarrollar en el IRICE es realizar en una zona marginal desde todos los puntos de vista, teniendo en cuenta las diferentes variables, por ejemplo: violencia sexual, violencia familiar, violencia social y otros aspectos, que están relacionados con el agua, los insectos, enfermedades infectocontagiosas, enfermedades sexualmente trasmitidas, problemas siquiátricos, psicológicos, hacinamiento. El propósito es ver cuál de todos esos problemas es el que puede movilizar a la población y hacer que se organice para resolverlo de modo tal, que aunque no sea el problema más grave 
sea el problema que pueda comenzar a generar una dinámica diferente. Igualmente, es importante establecer cuáles son los conceptos fundamentales que esa población tiene; investigar cuál es la apropiación de esos conocimientos y cómo se utilizan (identificar cuáles son los sectores que pueden transmitir esa información) y determinar qué tiene que saber esa población para resolver el problema.

Recién estamos empezando desde la escuela, que es de relativamente fácil acceso, y a partir de ésta ir hacia la comunidad, aunque el trabajo es muy lento.

DC:La Universidad Pedagógica Nacional en esta administración le ha apostado precisamente a ir a las zonas rurales con un proyecto en Valle de Tenza, dándole oportunidad a la gente del pueblo de acceder a la educación superior, allí la realidad es abrumadora. Aunque nuestra visón engrana con la visión rural, al aterrizar los programas no se puede ir a hablar literalmente de todos los textos clásicos de la biología porque no tiene sentido, es necesario contextualizar los contenidos ¿Usted qué piensa profesor?

RG: Los problemas y las soluciones están en las zonas rurales, pero habría que establecer un trabajo. Asimismo conocer las concepciones de la gente del campo, en el caso de los campesinos, los saberes del conocimiento tradicional, que muchas veces hay que conservar y transformar eventualmente. Todo lo que uno quiere hacer está en ese lugar, un curso de educación ambiental está ahí, con gente que no conoce la teoría pero conoce la información con mucha más precisión, siempre digo: Si yo estoy perdido en un desierto prefiero estar con un persona de la zona.

DC: ¿Usted diría que uno puede encontrar conceptos estructurantes tanto en el conocimiento tradicional como el conocimiento clásico?

RG: El problema son definiciones, en un conocimiento tradicional seguramente hay algo que es más importante y algo que es menos importante. El conocimiento tradicional tiene dos características: es empírico a largo tiempo y tiene una explicación mágica, una explicación referida a la cultura tradicional y en ese caso hay una contradicción, debido a que la explicación no da cuenta del fenómeno, pero éste está bien relatado por ejemplo, la planta cura pero por qué. Pero la diferencia está en que eso hace que el conocimiento tradicional sea mucho más fragmentado o que la integración no provenga de una reflexión sobre el conocimiento sino de la explicación de una cultura.

La ciencia es completa; no puede partir de cualquier conocimiento y llegar a cualquier otro y encontrar el camino, no hay zonas aisladas; los conocimientos 
tradicionales son como elementos separados y no se integran en un sistema de conocimientos, sino en un sistema onírico

DC: Retomando las ideas de conceptos estructurantes, ¿Profesor Gagliardi, cómo se puede aplicar los conceptos estructurantes a las clases de biología, por ejemplo, en cuanto a la célula u otro tema que usted tenga conocimiento?

RG: Con la célula hay un trabajo que hicimos en España con estudiantes de noveno o décimo año hace muchos años, la idea era enseñar célula sin utilizar ninguna palabra científica, ni nada que desconociera el alumno, y partir de su propia experiencia y observación. Entonces, los elementos fueron analizar las concepciones que estos estudiantes tenían sobre el sistema, sin mostrar ninguna entrada de la materia, de lo que se come y lo que entra al organismo. Al mismo tiempo, se hizo un análisis de concepciones sobre crecimiento; se les dio a los alumnos una silueta y se les dijo que la hicieran crecer, añadiendo otros trozos de papel, al hacerlo se dieron cuenta que no solo crecían por las extremidades sino que crecían homogéneamente.

Después de esto, comienzan a discutir el sistema de transporte y se les ocurre que éste puede ser la sangre porque en cualquier lado donde uno se corte hay sangre y además les da la idea de que el crecimiento se hace por todos los caminos. Nos podemos dar cuenta que han aprendido cuando dibujan al otro año un marciano y le colocan vasos sanguíneos y el corazón es una bomba de agua o una rueda de molino. Después de esto, el alumno imagina de otra forma; pero cuando el alumno tiene esa base y piensa en la célula, no como una cosa abstracta que está en un libro, sino como ese pequeño núcleo que debe existir para que pueda crecer, ahí cambian las cosas.

Otro ejemplo se puede ver cuando uno pregunta la transformación de materia en un ecosistema, cuando existe una capa de hojas en el suelo y tiene la misma altura todo el año. Algunos estudiantes de cursos avanzados responden que el viento se las lleva y otros dicen que el peso hace que se vayan aplastando, pero no está la idea de transformación, es una idea que no existe y ahí nace cómo mostrar procesos de transformación a partir de procesos visibles como el de las basuras; hay que trabajar mucho, hay que observar mucho a su alrededor, no hacer experiencias en clase sino hacerlo comprender lo que le pasa todos los días, así pueden correlacionar cada acto de su vida con lo que van aprendiendo

DC: De acuerdo con su experiencia Profesor, ¿Cómo se relacionan los conceptos estructurantes con los principios unificadores de la biología?

RG: Depende como se trate, si la célula es un tema, no es un concepto fundamental, el problema es que un concepto estructurante es un concepto 
científico. Tomando la célula como ejemplo, como el sistema más simple que permite generar y mantener las condiciones que dan lugar a la autoconstrucción, ahí en eso la idea de organismo multicelular es un concepto estructurante, pero la idea de que la célula es un sistema de relaciones múltiples es un concepto avanzado, hay un concepto al cual llamo célula pero para mí no es tanto la estructura celular, sino el hecho de que la célula divide el universo en dos sectores: el interior y el exterior, lo cual representa una unidad y la idea de autoconstrucción y autoorganización.

DC: ¿Cuál sería la recomendación usted haría en términos investigativos sobre la enseñanza de la biología y qué problemáticas se necesitan abordar actualmente?

RG: Fundamentalmente yo no voy a dar ninguna recomendación a un país que está trabajando tan bien como Colombia, y además, yo nunca doy recomendaciones a colegas, lo que podría decir, es que es importante analizar las concepciones y dificultades de aprendizaje. Se conoce mucho sobre las concepciones pero hay un fenómeno, el cual es la transformación de la sociedad a partir de la televisión, la informática, los fenómenos sociales y la ciencia, es decir, hace 15 años se le preguntaba a alguien en la calle sobre el ADN y esta persona decía: "esto debe ser una sociedad, una sociedad de seguros", hoy se le pregunta a cualquier persona y dice: "sí, en televisión he visto que se usa para pruebas de paternidad", entonces cambian las concepciones de la genética, pero el análisis de concepciones hay que hacerlo continuamente porque la sociedad cambia y si uno quiere adaptar la enseñanza a los alumnos, hay que hacerlo y además hay que compararlos, es decir, ver si en Colombia los niños o los adultos tienen las mismas concepciones que en Buenos Aires, Rosario, en Ginebra.

Por otra parte, el fenómeno de la televisión está ofreciendo un mecanismo de enseñanza, es decir, de transmisión de la información y el chico recibe información casi antes de aprender a hablar, el bebé está sometido a imágenes cargadas de emoción de colores, de música rápida, a fenómenos que duran segundos, los dibujos animados. ¿Será que ese chico que fue sometido a ese medio aprende de la misma manera como aprendíamos nosotros?, ¿tiene el mismo estilo de aprendizaje o no? ¿el mismo mecanismo? y si no ¿cómo adaptar la enseñanza?, es una cosa compleja que necesita tiempo.

La gente lee menos, por ejemplo en un programa de televisión en media hora te dan un resultado. Esto es otra forma de aprender y creo que las concepciones de los estudiantes y la televisión como mecanismo de enseñanza son los grandes temas de investigación. 